\section{VALOR DEL SUELO Y VIVIENDA, CONTENCIÓN AL CRECIMIENTO URBANO Y DENSIFICACIÓN EN BOGOTÁ 1969-2012}

Juan G. Yundaํ, Nicolás Cuervo Ballesteros²

\section{Resumen}

En 1979 Bogotá implementó un perímetro de crecimiento con un aumento de los límites de altura en el centro. Estas políticas buscaban proteger la ruralidad circundante y consolidar un centro denso y de uso múltiple. Estas políticas son criticadas internacionalmente con el argumento de que aumentan el precio del suelo, sin embargo, esto puede ser compensado con el aumento en los límites de altura para no afectar los precios de la vivienda. El presente estudio analizó los límites de altura y el incremento del precio del suelo, recopilando precios históricos de diferentes fuentes $y$

\section{LAND AND HOUSING VALUES WITHIN URBAN CONTAINMENT AND DENSIFICATION IN BOGOTÁ 1969-2012}

\author{
Juan G. Yunda, Nicolás Cuervo Ballesteros
}

\section{Abstract}

In 1979, Bogotá implemented an urban growth boundary with an increase in height limits in central areas. These policies were aimed to protect the surrounding rural areas and consolidate a dense and multi-use city center. Internationally, these policies are criticized arguing that they increase the prices of urban land, which is opposed by the argument that this increase is compensated by raising height limits to avoid higher housing prices. The present study analyzed the height limits and the increase in the price of homes and land, gathering historical prices from different sources and crossing these 
cruzando estos datos con las normativas de alturas de cada época. Los resultados muestran que los aumentos del límite de alturas y su aprovechamiento, por medio de la inversión inmobiliaria, fueron diferenciados y contrarios a las intenciones de los planes de ordenamiento, siendo estos aumentos mayores en las zonas de estrato social alto, moderados en estrato medio, y menores e incluso negativos para el estrato bajo. El suelo en el sector de estrato alto tuvo una valorización de más de diecisiete veces, mientras que los precios de la vivienda permanecieron estables; la valorización fue mucho menor en el estrato bajo y la vivienda es ahora más costosa.

PALABRAS CLAVE: PERÍMETROS CRECIMIENTO URBANO; DENSIFICACIÓN; VALOR DEL SUELO; VALOR DE VIVIENDAS; BOGOTÁ

Received: 2019-08-28

Accepted: 2020-05-19 data with the height regulations of each era. The results show that the increases in the height limits and their use by real estate investment were differentiated and contrary to the intentions of zoning plans, greater in the areas of high social stratum, moderate in the middle stratum, and smaller and even negative for the low stratum. The land in the high stratum sector increased more than seventeen times in value while housing prices remained stable; the valuation was much lower in the lower stratum and housing is now more expensive

\section{KEYWORDS: URBAN GROWTH BOUNDARY; DENSIFICATION; LAND VALUE; HOUSE VALUE; BOGOTÁ}

Recibido: 2019-08-28

Aceptado: 2020-05-19
1 Profesor asistente, Facultad de Arquitecturay Diseño, Pontificia Universidad Javeriana, Colombia, http://orcid. org/0000-0002-3459-6880. Correo electrónico: yunda.j@ javeriana.edu.co
2 Profesor investigador, Escuela de Economía, Universidad Sergio Arboleda, Colombia, https://orcid.org/0000-00022045-0485. Correo electrónico: nicolas.cuervo@usa.edu.co 


\section{Introducción}

Durante la segunda mitad del siglo XX el discurso ambientalista permeó la teoría de la planeación urbana originando el pensamiento de crecimiento urbano inteligente. Alrededor de este, surgieron políticas que buscaban gestionar la expansión urbana para evitar el crecimiento disperso y socialmente segregado que afecta los entornos naturales e incentiva prototipos de vivienda dependientes del automóvil privado. Ejemplos de políticas son los Perímetros de Crecimiento Urbano (PCU), que han sido implementados bajo modalidades como los cinturones verdes-aplicados a las ciudades de Inglaterra en la década de 1950-60, los perímetros límites de crecimiento-del que fue pionera la ciudad de Portland en Estados Unidos en 1979, y los perímetros de servicios, que impiden la prestación de servicios públicos fuera de estos-como el que implantó Bogotá también en el año de 1979.

La principal crítica a los PCU indica que disminuyen la disponibilidad de suelos para urbanización e incrementan el valor del suelo urbanizado. Este incremento puede subir los precios de la vivienda si no se acompaña con políticas que aumenten los límites de densidad dentro del perímetro. Por ejemplo, si los PCU se acompañan de aumentos en el límite de la altura de las edificaciones, el incremento en el costo del suelo será compensado con el aumento de las unidades de vivienda que pueden ser desarrolladas en un predio.

En este contexto, el estudio busca relacionar el incremento de las alturas máximas permitidas con cambios del precio del suelo y de la vivienda en Bogotá, desde antes de la implementación del PCU y su evolución en el tiempo. El argumento central es que la implementación del PCU, que busca consolidar un centro denso y de uso múltiple, tiene efectos diferenciales y por lo general más favorables para zonas centrales con altos precios de la vivienda, tanto por el atractivo inmobiliario ligado a los precios como por un tratamiento normativo más favorable. Los resultados del estudio aportan al estudio del valor del suelo y la vivienda urbana y al desempeño de las políticas de crecimiento inteligente y sus múltiples estilos de implementación.

\section{EXPERIENCIA INTERNACIONAL}

En Estados Unidos, los estudios muestran que los PCU incrementan el precio del suelo, pero no hay consenso sobre su efecto en los precios de la vivienda. El caso más estudiado es Portland, Oregon, que implementó un PCU en 1979. Pese a que la ciudad experimentó un aumento de los precios del suelo en la década de 1990, no se ha podido probar que los aumentos en el precio de las viviendas hayan sido significativamente diferentes a los de otras 
ciudades de EEUU (Downs, 2002; Jun, 2006; Mathur, 2014; Phillips y Goodstein, 2000). Sin embargo, investigadores han probado también que los PCU disminuyen la oferta de vivienda de bajo costo, por lo cual las ciudades deberían especificar metas en producción de vivienda para los diversos segmentos del mercado, ya que los PCU tienen efectos diferenciados según el segmento. (Addison, Zhang y Coomes, 2013; Aurand, 2010; Mathur, 2019). Estudios internacionales muestran que no siempre los promotores responden a los incentivos de aumento de densidad, y que los efectos de los PCU dependen del estilo de su implementación, las características del mercado local de vivienda y lo patrones de propiedad de la tierra (Dawkins \& Nelson, 2002).

En Hispanoamérica, los estudios sobre PCU son escasos, y se enfocan en la poca eficiencia de su implementación (Aguilar y Olvera, 1991). Hay muchos estudios que intentan explicar los valores del suelo y vivienda a través de la diversidad de factores que los afectan. Roca Cladera (1983) evaluó diferentes factores, como la accesibilidad, la calidad urbanística y la jerarquización social en los precios del suelo de Barcelona, encontrando que las variables de jerarquización social fueron las que mejor explicaron la estructura del mercado del suelo y vivienda. Esta jerarquización social puede ser representada a través de los estilos arquitectónicos. Por ejemplo, en Santiago se encontró que el valor de un inmueble es producto de la interacción entre el valor del suelo y las características arquitectónicas, que dependen de una segmentación social del mercado inmobiliario (Encinas, Marmolejo y Aguirre, 2016). Reforzando este punto, en Costa Rica y México también se ha encontrado que en el valor del suelo intervienen factores vinculados con las representaciones sociales, el ingreso y la educación de los consumidores (Dillon y Cossio, 2011; Quintana, Ojeda y García, 2018).

En torno al impacto de la accesibilidad en precios de suelo y vivienda en Latinoamérica se ha estudiado el impacto de la introducción de los sistemas de Transporte Rápido de Buses (TRB) en el desarrollo urbano y en la valoración de sectores. A pesar de que en Bogotá se encontró un impacto de los sistemas TRB en los precios de renta (Rodríguez y Targa, 2004), otro estudio plantea que no hay efecto en los precios del suelo (Estupiñan, 2011). Estudios más amplios encontraron que la movilidad es sólo uno de los factores que predice el desarrollo urbano, siendo otros: la actitud de los promotores, las condiciones del mercado, la disponibilidad de suelo y la zonificación (Rodríguez, Vergel-Tovar y Camargo, 2016).

\section{BOGOTÁ, MERCADO SEGMENTADO DE VIVIENDA Y ZONIFICACIÓN}

Bogotá ha sido clasificada como una ciudad con diversidad de prototipos de vivienda polarizada entre un urbanismo de origen formal, para los estratos sociales altos y medios, y un urbanismo 
informal para los estratos sociales bajos (Griffin y Ford, 1980). Diferentes autores muestran como esta polarización influye en el mercado de vivienda creando un entorno segmentado determinado por un valor de la vivienda que depende tanto de factores económicos como sociales. Jaramillo (2009) indica que el valor del suelo en Bogotá depende de tres factores; dos que son tradicionales en el contexto internacional-la proximidad a las fuentes de empleo y la normativa de densidades y usos de suelo- y un factor que el autor llama "renta de segregación" que da valor monetario al estatus social de un sector de ciudad.

Borrero Ochoa (2010) propone que este estatus social se vea reflejado en el sistema local de distribución de subsidios para el pago de tarifas de servicios públicos llamado "estratificación socio-económica." Este sistema asigna a cada vivienda de la ciudad un "estrato" de acuerdo a las características del urbanismo y la vivienda según la manzana en la cual esté ubicada, como lo indica la Figura 1. El estrato sube de 1 a 6, siendo categorizadas en estrato 1 y estrato 2 , manzanas desarrolladas con un urbanismo informal —el 7 y 33\% de las viviendas de la ciudad respectivamente-; el estrato 3, son las áreas antiguas de ciudad y los complejos multifamiliares de bajo costo -el 36\% de las viviendas-; y el estrato 4, 5 y 6 , son las áreas desarrolladas formalmente subiendo de acuerdo a la calidad percibida de su urbanismo y vivienda —respectivamente el 15, 5 y $4 \%$ de las viviendas (Secretaría Distrital de Planeación [SDP], 2016). Los estratos permiten aplicar subsidios cruzados al pago de servicios públicos como el agua y la electricidad. Como ejemplo: para el agua, las viviendas clasificadas en estrato 1, 2 y 3 pagan un valor subsidiado para el consumo básico de hasta $19 \mathrm{~m}^{3}$ al mes. El estrato 4 paga el valor de costo del servicio y los estratos 5 y 6 pagan un aporte adicional al costo del servicio (Acuerdo 659, 2016). Si bien, el indicador de estrato no incluye como variable el ingreso familiar, este indicador ha sido ampliamente asimilado por la sociedad como un indicador de estatus social y se le responsabiliza de agravar la segregación socioespacial (Uribe-Mallarino, 2008). Según Borrero Ochoa (2010, p. 18) el crecimiento urbano en Bogotá se orienta desde los estratos altos (5 y 6) que buscan alejarse de las áreas desarrolladas informalmente (estratos 1 y 2).

Esto sugiere que el mercado de vivienda en Bogotá es influenciado por el concepto de estatus social, territorializado en sub-mercados de vivienda que pueden ser observados en el indicador local de estrato. La segmentación del mercado de vivienda en sub-mercados de acuerdo al poder adquisitivo de las familias no es un fenómeno exclusivo de Bogotá, ya que ha sido identificado en diferentes contextos (Islam y Asami, 2009; Meen y Andrew, 2004; Omer y Goldblatt, 2012; Schnare y Struyk, 1976). Existen otros factores de valorización del suelo, como una ubicación privilegiada en función de 
la accesibilidad a fuentes de empleo y los valores paisajísticos de una ciudad; sin embargo, éstos no son el punto central de este estudio.

Esta segmentación del mercado de vivienda puede también estar acentuada por la normativa de zonificación de la ciudad y las preferencias de los promotores de vivienda. Mientras los promotoresbuscanfocalizarsuinversiónenáreas de estratos más altos, que son más rentables, la zonificación permite edificaciones de mayores alturas en estas mismas áreas (Yunda, 2019). La zonificación también puede permitir mayores alturas en otras áreas de estratos más bajos, pero debido a que las decisiones de inversión dependen exclusivamente de los promotores, este aprovechamiento de la norma puede sub-aprovecharse o, simplemente, no darse. Este fenómeno es causado por un régimen de zonificación que busca incentivar la acción de los promotores privados de vivienda sobre la intervención del estado en la estructura urbana. Por esto los historiadores del urbanismo han llamado a este período de zonificación como "La Ciudad Inmobiliaria" (Saldarriaga-Roa, 2000), "Planificación Económica" (Cortés Solano, 2007) o "La Planeación de la Ciudad como Negocio" (Salazar-Ferro, 2017). Estas teorías pueden enmarcarse en un planeamiento de la ciudad latinoamericana clasificado como "neoliberal" (Brites, 2017).

\section{Metodología, casos de estudio y fuentes documentales}

El análisis muestra la evolución general de la norma y de los precios inmobiliarios en la ciudad y se concentra luego en cuatro zonas que poseen información continua sobre el precio del suelo en el período 1960-2012. Cada una de estas zonas está asociada a un segmento diferente del mercado evidenciado a través del indicador local de estrato. El segmento de mayor precio es el estrato 6 , y como caso de estudio tomamos la zona donde se encuentra el barrio Chicó. Este es un barrio desarrollado entre 1930 a 1950, inicialmente compuesto de grandes parcelas con casas unifamiliares aisladas entre grandes jardines, con diferentes estilos arquitectónicos europeos como neotudor inglés, alemán, neoclásicas o modernas, construidas para las élites sociales de la época. Descendiendo en valor de vivienda se encuentra el estrato 5, cuya zona de estudio incluye al barrio Santa Bárbara. El barrio Santa Bárbara fue desarrollado entre 1950 y 1970 y está compuesto por parcelas de tamaño grande ocupadas por viviendas unifamiliares aisladas, de estilo arquitectónico californiano con antejardines y patios traseros, imitando el suburbio del automóvil norteamericano. 
FIGURA 1. ESTRATIFICACIÓN DE BOGOTÁ Y SECTORES DE ESTUDIO.

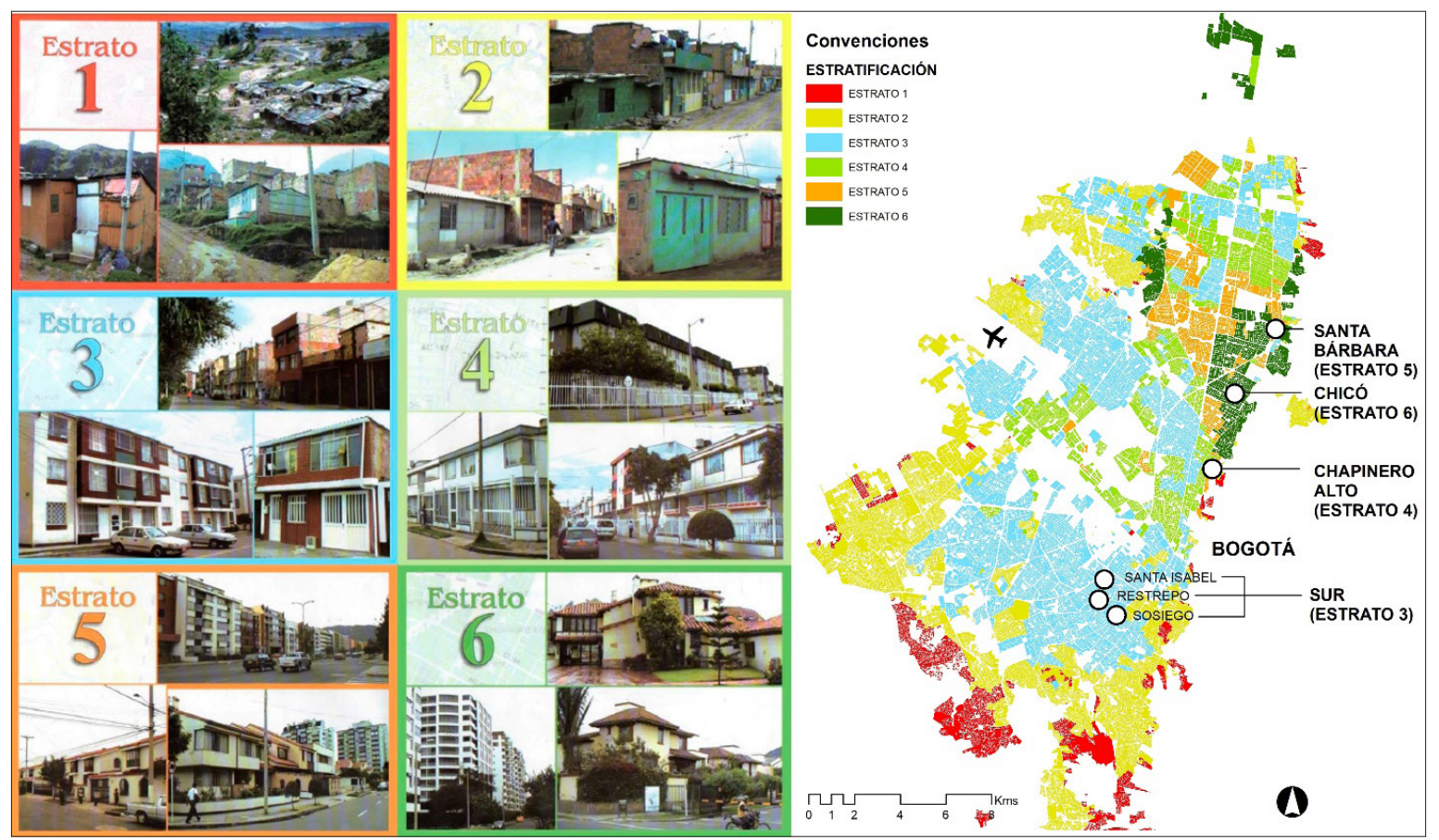

Fuente: Elaboración propia adaptada de Departamento Administrativo de Planeación Distrital (2004) y Decreto 291 de 2013. 
Como ejemplo del siguiente segmento descendiendo, o estrato 4, la zona de estudio incluye el barrio Chapinero Alto. Este barrio se encuentra al oriente de la ciudad en terreno de piedemonte y fue desarrollado entre 1940 a 1960. Los terrenos fueron subdivididos en parcelas para construir casas entre medianeras con reducidos antejardines y patios traseros. Estas casas para familias de ingresos medios eran versiones más pequeñas de las casas de Chicó o Santa Bárbara. Finalmente, en el segmento bajo del mercado, incluimos en este estudio los únicos barrios de estrato 3 con información de precios desde la década de 1960. Entre ellos se encuentran los barrios Santa Isabel, Restrepo y Sosiego desarrollados entre 1940 a 1960. Estos barrios, originalmente para familias de "clase obrera", están compuestos por casas entre medianeras producto de un diseño de maestro de obra sin intervención de arquitecto. Estas casas entre medianeras carecen de antejardín o patio trasero y ocupan la totalidad del predio. En los estratos 1 y 2 no se tomaron casos de estudio ya que estas zonas son más recientes y no hay información de los precios del suelo en los períodos y bases de datos utilizados.

Para analizar la zonificación y valores del suelo utilizamos fuentes mixtas tanto cualitativas como cuantitativas, en tres componentes. El primer componente comprende un análisis de la evolución de la normativa de zonificación, específicamente de los límites de altura, en los años 1960 -antes de la implantación del
PCU-y durante la vigencia del PCU, desde 1979 hasta 2012. Esta cronología enmarca cuatro normativas: 1) el Decreto 1119 de 1968; 2) el Acuerdo 7 de 1979; 3) el Acuerdo 6 de 1990; y 4) el "Plan de Ordenamiento Territorial de Bogotá D.C.", compilado por el Decreto 190 de 2004. Para cada uno de los períodos se localizaron los sectores correspondientes a cada uno de los cuatro casos de estudio, identificando las alturas máximas permitidas al interior de los barrios. Excluimos algunos casos especiales como predios con frente a vías principales o agrupaciones de vivienda donde los límites de altura son diferentes a los predominantes en el barrio.

Como segundo componente analizamos las edificaciones, los valores del suelo y de la vivienda en el periodo 1960-2012. La información de precios se obtiene de dos fuentes: las de suelo provienen de la Lonja de Propiedad Raíz de Bogotá, que publica información desde 1960 para un número creciente de zonas de la ciudad a partir de información de transacciones o avaluaciones hechas por sus afiliados; y las de la vivienda son las cifras calculados por el Observatorio CEDE (Jaramillo \& Cuervo, 2014) a partir de ofertas en prensa de venta y alquiler de vivienda. Los precios se expresan en pesos por metro cuadrado. Para este trabajo, se utilizaron precios reales de 2012, año de referencia que permite expresar en términos comparables los precios del suelo y de la vivienda. 
La lonja considera sectores con diferentes usos —residencial, comercial, industrial, mixto- de los cuales examinamos solamente los sectores residenciales, divididos en dos grupos. El primer grupo son 19 sectores residenciales con información continua desde 1969 hasta 2012, cuya evolución se analiza en términos promedio y de su variabilidad espacial. Utilizamos el "coeficiente de variación" que corresponde a la desviación estándar del precio dividida por el promedio, representando la variabilidad desigualdad o divergencia- de precios entre sectores de la ciudad permitiendo comparar la variabilidad de valores que cambian de magnitud entre observaciones.

Por otra parte, analizamos los precios del suelo de las cuatro zonas de estudio mencionadas anteriormente, cuyos valores están expresados en precios reales, por metro cuadrado, del año 2012. Específicamente, el Chicó incluye las zonas de observación "La Cabrera", "Chicó Reservado", "Chicó" y "Santa Bibiana"; Santa Bárbara, las zonas "La Carolina", "Multicentro", "Santa Barbara Occidental", "Calleja Baja" y "Bella Suiza"; Chapinero Alto, la zona "Chapinero Alto"; finalmente Sur, que incluye las zonas "Suroriente 1" y "Suroriente 2", que hoy configuran los barrios Santa Isabel, Restrepo y Sosiego.

El tercer componente de información concierne a la altura de las edificaciones según fecha de construcción y proviene del Catastro de Bogotá vigencia 2012. La base catastral incluye información a nivel de predio, del área construida, el uso, la fecha de construcción y la altura. A partir de esta fuente se hace un análisis retrospectivo de la altura de las edificaciones, siendo el indicador construido el porcentaje de área construida en edificaciones según su fecha de construcción y su altura, en categorías que coinciden con los cambios de norma y las alturas permitidas. Para estas cuatro zonas de estudio se analizará de manera conjunta la evolución de los precios de la vivienda, del suelo, de la norma urbana y de la altura de las edificaciones, permitiendo observar la interacción de estas variables manteniendo constantes los sectores de análisis.

\section{Norma urbana, altura y precios inmobiliarios 1960 . 2012}

La ciudad de Bogotá en el período analizado tuvo cuatro esquemas de norma urbana de usos de suelo y densidades y/o alturas máximas que afectaron los sectores del estudio, que se muestran en la Figura 2. Estos cambios de estatutos se convirtieron en norma oficial a través de "decretos" o "acuerdos" siendo los decretos órdenes ejecutivas tomadas por el alcalde individualmente y las disposiciones establecidas en consenso con el Concejo de la ciudad. 
La primera normativa del período se denominó Decreto 1119 de 1968, titulado "Plano Oficial de Zonificación General de la ciudad." Esta normativa estaba basada en una serie de planes y estudios realizados en la ciudad durante la década de 1960, entre ellos el Plan Distrital de 1961 y el Plan Distrital de 1964 (Departamento Administrativo de Planificación Distrital [DAPD], 1964; Saldarriaga-Roa, 2000, p. 118123). El principio fundamental fue organizar la ciudad en una serie de sectores diferenciados de acuerdo con el nivel de densidad de habitantes, que reflejaba la división social en sectores de estrato alto con densidad baja, sectores de estrato medio con densidades medias, y sectores de estrato bajo, o "obreros", con densidades altas. Como lo indica el primer plano de la Figura 2, se establecieron tres categorías: Zonas Residenciales Urbanizables en Densidad Baja (UDB) con códigos R-0, R-1 y R-2; Zonas Residenciales en Densidad Media (UDM) con códigos R-3, R-4 y R-5; y Zonas Residenciales Urbanizables en Densidad Alta (UDA) con códigos R-6, R-7. R-8 y R-E.

Más adelante, se estableció una nueva zonificación a través del llamado Acuerdo 7 de 1979, "Por el cual se define el Plan General de Desarrollo Integrado y se adoptan políticas y normas sobre el uso de la tierra en el Distrito Especial de Bogotá." Como menciona Saldarriaga-Roa (2000, p. 131-135) el Acuerdo 7 se basó en consideraciones de índole económica para contener y regular el crecimiento urbano con dos estrategias principales. La primera fue el establecimiento de un PCU, y la segunda fue la densificación de las zonas centrales de la ciudad definida por rangos de densidad, estimulando la renovación urbana a través del reemplazo de vivienda unifamiliar por vivienda multifamiliar.

Para lograr estos objetivos, el Acuerdo 7 introdujo el concepto de "tratamientos", que eran los sectores normativos con diferentes límites de altura y densidad, de acuerdo a los objetivos estratégicos de la ciudad. Las áreas centrales de la ciudad estaban divididas en zonas con tratamiento de "Conservación" -en sectores donde se buscaba conservar los niveles de densidad y forma de las edificaciones de vivienda, y zonas con tratamiento de "Rehabilitación," en sectores donde se buscaba incentivar una transición de unifamiliares a multifamiliares, como las áreas residenciales en baja altura — Residencial de Rehabilitación, RR_ y las áreas centrales de uso mixto Actividad Mixta de Rehabilitación AMR.

El siguiente plan, llamado Acuerdo 6, "Por medio del cual se adopta el Estatuto para el Ordenamiento Físico del Distrito Especial de Bogotá," se estructuró como evolución del Acuerdo 7 utilizando las mismas herramientas de zonificación que los tratamientos. Sin embargo, esta evolución llevó a hacer la zonificación más compleja, ya que los tratamientos se empezaron a fraccionar en varias categorías, lo que hizo más difícil la 
FIGURA 2. EVOLUCIÓN DE LA ZONIFICACIÓN EN BOGOTÁ 1960-2011.

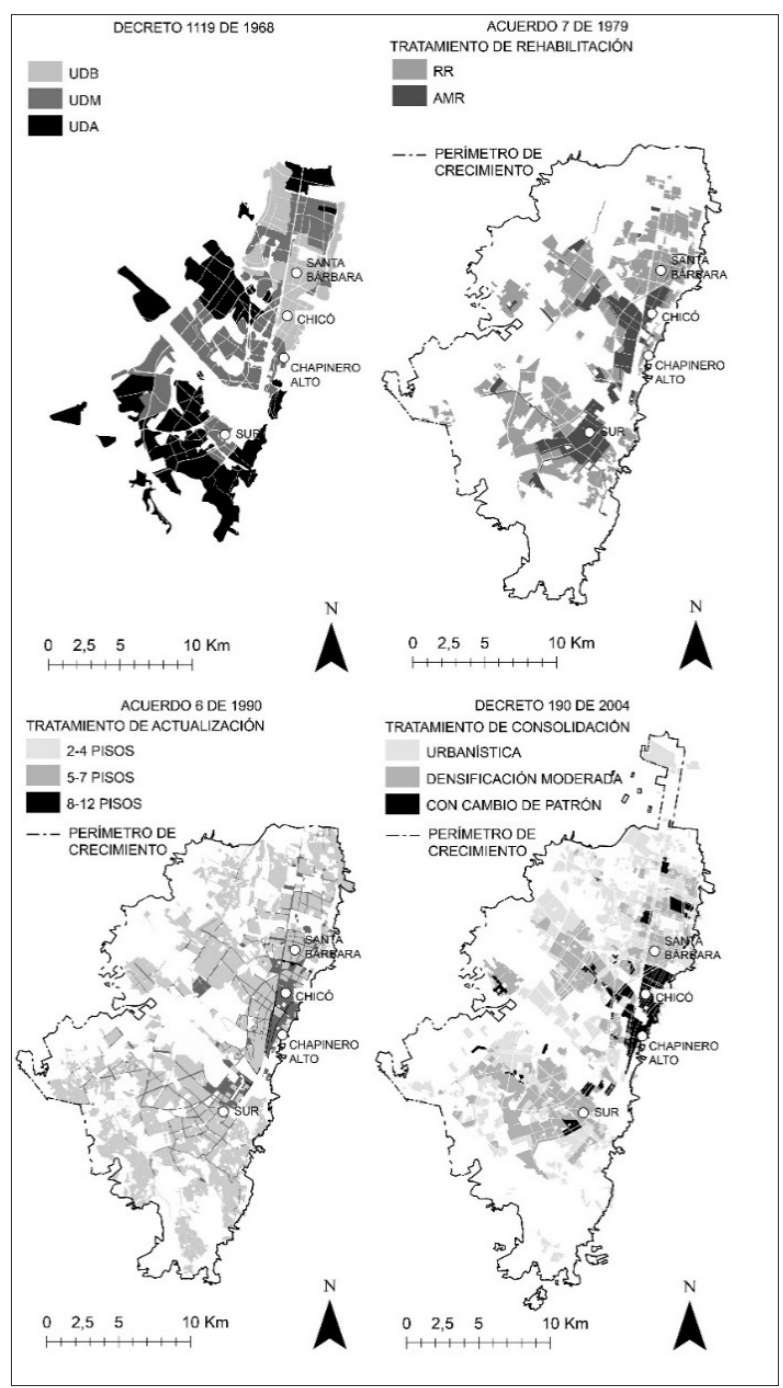

Fuente: Elaboración propia basada en los Decretos y Acuerdos señalados. 
interpretación de las normas (Saldarriaga-Roa, 2000, p. 136-137). Al igual que el Acuerdo 7, el Acuerdo 6 formuló con posterioridad dos decretos para establecer las normas volumétricas específicas de los tratamientos: el 735 y el 736 de 1993. Esta vez el tratamiento de Rehabilitación pasó a llamarse "Actualización" y se establecieron varias categorías de áreas residenciales. La norma introdujo el límite de altura a las diferentes zonas -bajo el concepto de "volumetría"- de dos a cuatro pisos en las áreas periféricas y de cinco a siete pisos en la zona norte de la anterior área de Actividades Múltiples. Sin embargo, en la zona sur, en la práctica, se redujeron los límites de altura. Las grandes alturas de ocho a doce pisos se permitieron solo sobre las grandes avenidas.

Con base a la nueva ley orgánica nacional de ordenamiento territorial, llamada Ley 388 de 1997, la ciudad de Bogotá estableció su primer Plan de Ordenamiento Territorial, Decreto 190 compilado en 2004. El Decreto 190 derogó el PCU heredado del Acuerdo 7 y el Acuerdo 6, pero condicionó la expansión de la ciudad a la formulación de Planes Zonales que establecieran un reparto equitativo de las cargas y beneficios de la urbanización entre la ciudad y los promotores privados de vivienda. Sin embargo, hasta el 2019 -quince años después- ninguno de estos Planes Zonales se ha desarrollado, por tanto, efectivamente el PCU ha tenido continuidad. Al interior de la ciudad, el Decreto 190 estableció un sistema jerarquizado de planeación donde las normas generales se establecían a escala de ciudad y las específicas de los barrios a través de unas normativas locales llamadas "Unidades de Planeación Zonal" (UPZ). Igualmente, se continuó la tradición de establecer las normas de volumetría a través de los tratamientos, cambiando nuevamente los nombres y estableciendo nuevas modalidades para cada uno de ellos. Por ejemplo, el tratamiento de Actualización pasó a ser llamado "Consolidación" y se introdujeron tres modalidades: Consolidación Urbanística -en aquellos barrios donde la volumetría no se alteraba, Consolidación Con Densificación Moderada -donde se permitía un aumento moderado de los límites de altura, y Consolidación Con Cambio de Patrón -donde se buscaban mayores aumentos de densidad.

El desarrollo efectivo de la densificación de la ciudad, promovida por la norma entre 19682011, se puede observar con los datos del catastro. La Figura 3 muestra la altura de las edificaciones registradas en 2012 según su fecha de construcción agrupada en períodos normativos. Estos porcentajes deben ser interpretados como una estimación del área desarrollada en cada período. La composición por alturas es similar a la obtenida por otros trabajos que analizan información de licencias de construcción (Jaramillo, Parias y Llano, 1993). En la Figura 3 se puede observar que a pesar de que el PCU fue implementado en 1979, sólo fue hasta el período más reciente, después 
de 2004, que la ciudad tuvo un proceso de densificación significativo. Las cifras muestran que la implementación del PCU, entre 1979 y 2004, coincide con un aumento moderado de la construcción en altura, que pasa a representar el 15\% de la nueva área construida -en un período que fue también el de mayor crecimiento demográfico de la ciudad. Sin embargo, es a partir del Decreto 190, en 2004, cuando la ciudad se densifica de manera considerable. El $40 \%$ de las nuevas edificaciones de la ciudad tuvieron una altura mayor a cuatro pisos en 2011, y aproximadamente un 33\% tuvo una altura mayor a seis pisos. Esto puede estar relacionado a que en este último período se rellenaron casi totalmente los predios aún vacíos dentro del PCU, y a unas normas generosas en límites de altura.

Por su parte, los precios del suelo aumentan sostenidamente -Figura 4-de manera compatible con los cambios esperados por la implementación del PCU y el aumento de altura de las construcciones. Las diferencias de precios entre sectores de la ciudad -medidas mediante el coeficiente de variación-han crecido en el tiempo, particularmente durante la década de 1980, con la implementación del PCU. Es así que durante este período las diferencias de precios del suelo adquieren su magnitud actual y fluctúan después según la coyuntura de precios -aumentando cuando los valores están al alza y disminuyendo en períodos de menor dinamismo. Los primeros años de vigencia del Decreto 190 muestran un aumento de los precios y de sus diferencias entre sectores de la ciudad. Esta tendencia se inscribe en el contexto de recuperación de la profunda crisis de fin de siglo XX, bajo el cual la nueva norma pudo contribuir a la valorización selectiva de los sectores con normativa de altura más favorable. Los últimos cuatro años merecen una anotación especial, pues en este período se observa una dinámica inusual de crecimiento de los precios del suelo de manera simultánea a la disminución de sus diferencias espaciales debido al mayor crecimiento de los precios en sectores de bajos precios. Esta particularidad no pone en cuestión la tendencia general de un nivel de precios que aumenta en la década de 1990 y en particular desde 2002 y unas diferencias espaciales que crecen durante los años 80 y conservan una magnitud comparable desde fines de la década de 1980.

Como se aprecia en la Figura 5, los precios de la vivienda muestran un comportamiento fluctuante, alrededor de un precio relativamente estable en el largo plazo, de un apartamento de dos habitaciones de 177 millones de pesos (cerca de 55.000 dólares). Las fluctuaciones siguen los ciclos macroeconómicos del país, entre los cuales se cuentan las dificultades de los años 80 , un corto pero intenso auge durante los primeros años de la década de 1990 (seguido de una profunda crisis nacional del sistema hipotecario) y la recuperación de la crisis y el auge de precios continuo desde inicios de los 
FIGURA 3. ÁREA CONSTRUIDA SEGÚN PERIODO NORMATIVO Y ALTURA, 1968-2012.

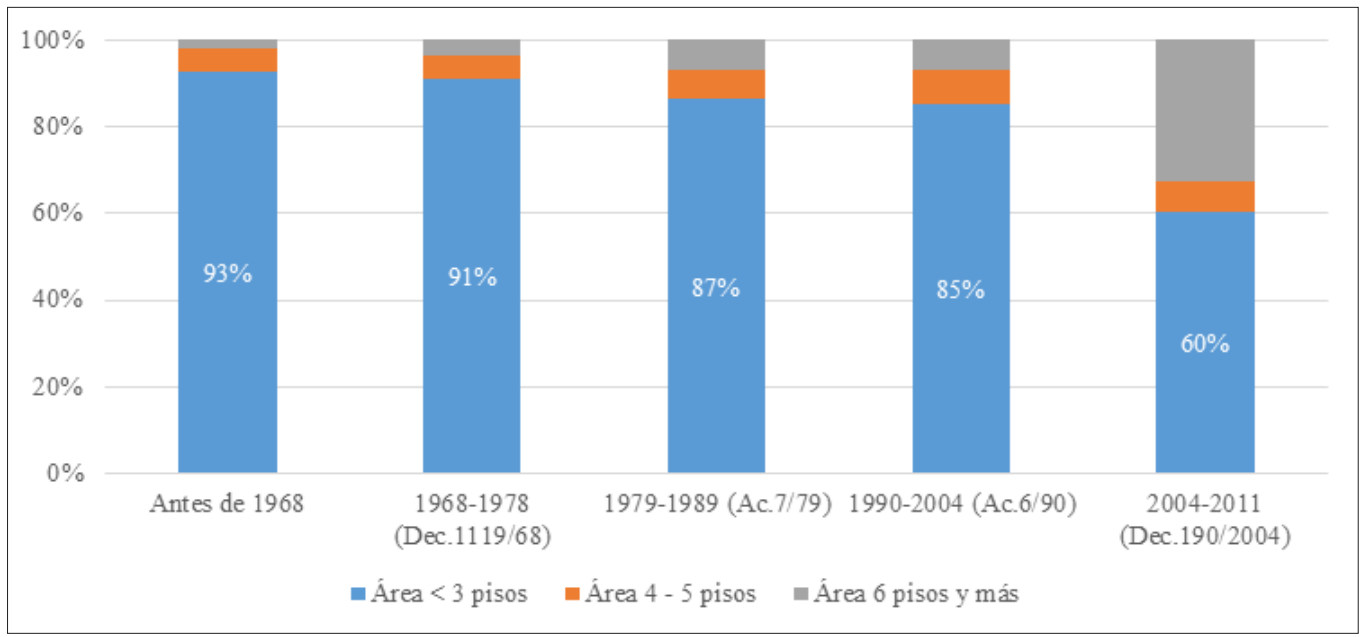

Fuente: Elaboración propia basada en información del Catastro de Bogotá.

FIGURA 4. PRECIO DEL SUELO EN BOGOTÁ, PROMEDIO Y COEFICIENTE DE VARIACIÓN, 1969-2016.

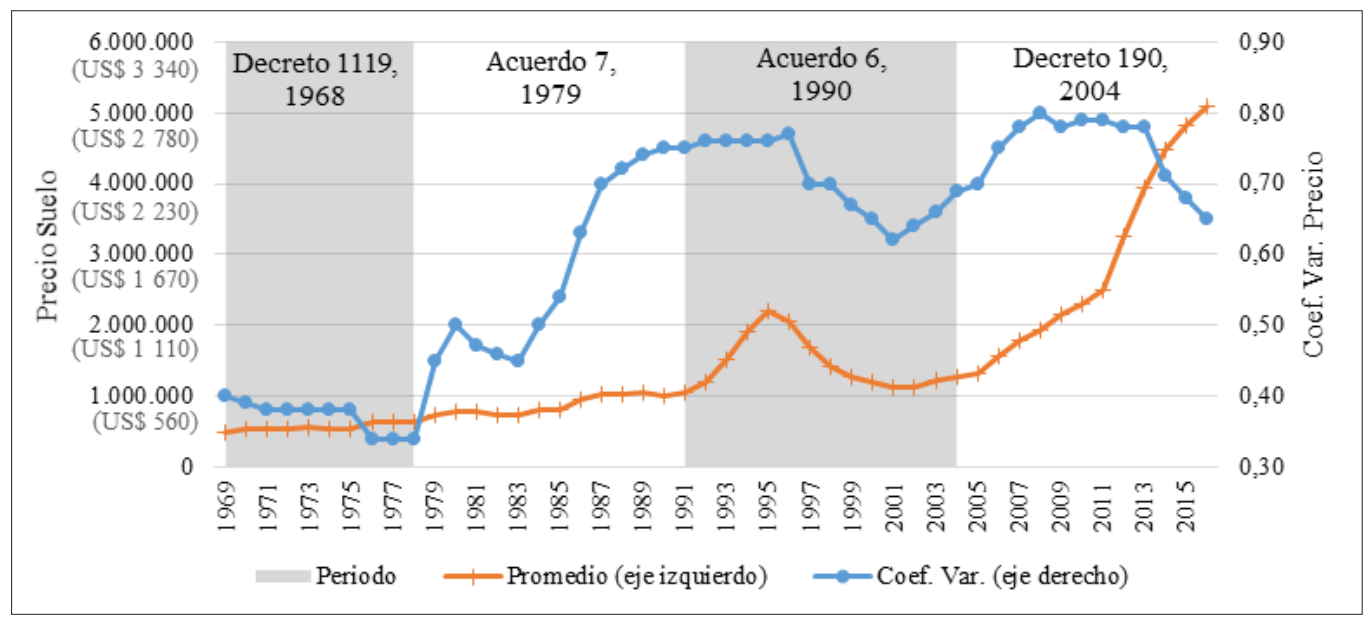

Fuente: Elaboración propia a partir de Lonja de Propiedad Raíz de Bogotá. 
FIGURA 5: PRECIO DE LA VIVIENDA EN BOGOTÁ, PROMEDIO Y COEFICIENTE DE VARIACIÓN, 1970-2012.

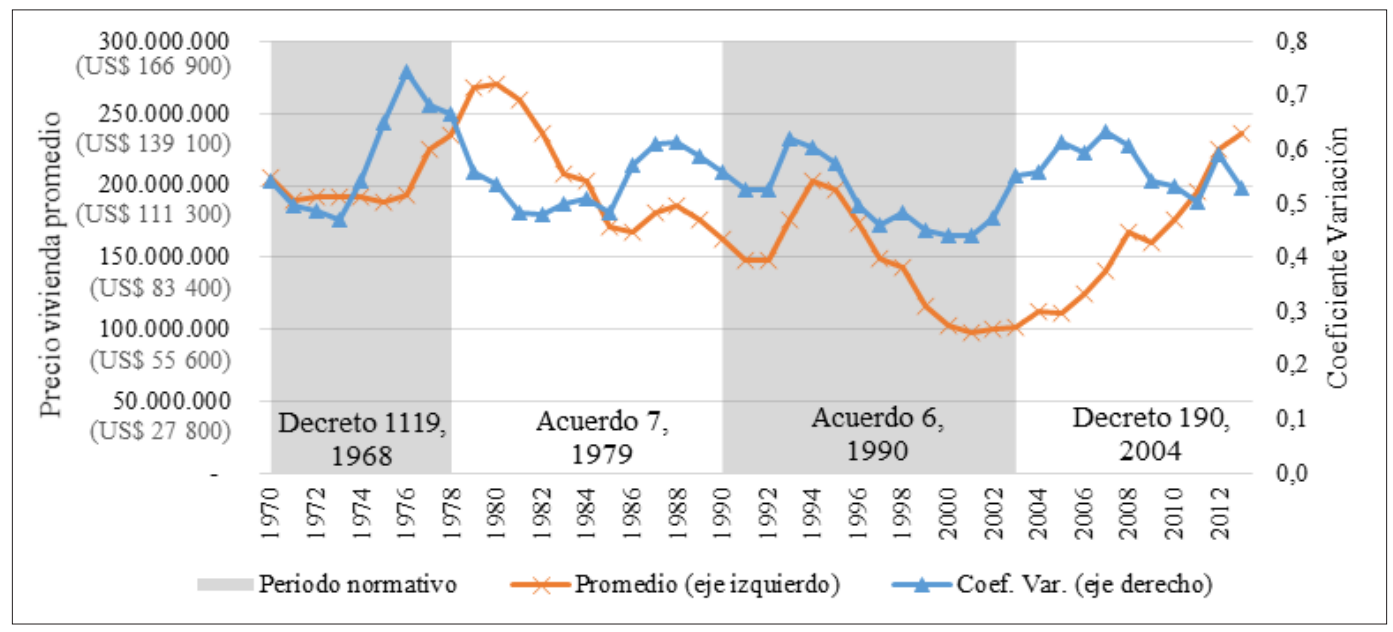

Fuente: Elaboración propia a partir de Observatorio CEDE

años 2000. Si bien la estabilidad de los precios promedio de la vivienda contrasta con el crecimiento de los precios del suelo observado durante el mismo período, este resultado es comprensible teniendo en cuenta la reducción en los costos de construcción y el aumento en la altura de las construcciones evidenciada durante el mismo período, tal y como lo espera la implementación del PCU y el aumento de la norma de alturas.

Las evoluciones señaladas hasta acá en términos agregados para Bogotá son compatibles con las tendencias esperadas por la implementación de un PCU. Desde la norma se limita el crecimiento por fuera de un límite establecido, pero se aumentan las alturas permitidas en diferentes sectores de la ciudad. Esta estrategia permite que las edificaciones en la ciudad aumenten su altura resultando en mayores precios del suelo sin que esto implique aumentos en el largo plazo de los precios de la vivienda.

Sin embargo, la evolución normativa y las tendencias de los precios de suelo y de la vivienda detallada para los casos de estudio permiten reflexionar sobre la traducción de la norma urbana en desarrollo inmobiliario. Los cuatro sectores examinados muestran un desarrollo, más intenso en sectores de altos 
precios, que escapa a las trayectorias asimilables a la gentrificación de ciudades latinoamericanas y constituye un factor de inercia, e incluso de ampliación, de las diferencias socio-espaciales de Bogotá.

De acuerdo al Decreto 1119 de 1968, las zonas de Chicó, Santa Bárbara y Chapinero Alto fueron clasificadas como sectores UDB (baja densidad). Estas zonas establecían un límite de altura de dos pisos para vivienda unifamiliar, de tres pisos para bifamiliar $y$, para viviendas multifamiliares, un límite de altura que respetara un índice de construcción -relación entre el área de la parcela y el área total construida- de 2.7, sin exceder dos veces el ancho de la vía. Los barrios analizados tienen calles estrechas, de un promedio de seis metros, lo que limitaba los multifamiliares a una altura de cuatro pisos, aproximadamente. La zona sur fue clasificada por el Decreto 1119 como densidad media UDM que, sin embargo, establecía límites de altura exactamente iguales a los de la zona UDB. Las altas densidades estaban representadas en mayores áreas de ocupación permitida; así, mientras que en UDB estaban limitadas al 60-65\% de la parcela, en UDM se permitía llegar a 70-75\% de la parcela.

La normativa del Acuerdo 7 de 1979, reglamentada con los Decretos 823 y 824 en 1980, dispuso todos los casos de estudio con el tratamiento de Rehabilitación, pues se consideraba que estas zonas podían tener mayores densidades que compensaran las restricciones a la expansión establecidas por el PCU. En cuanto a los usos del suelo, el Acuerdo 7 determinó áreas de usos mixtos en Chicó y Sur con el código AMR ("Actividad Múltiple de Rehabilitación") con una altura máxima ampliada a cinco pisos. Las zonas de Santa Bárbara y Chapinero Alto conservaron el uso principal residencial con el código RR ("Residencial de Rehabilitación") pero las alturas variaron, manteniéndose como límite tres pisos en Santa Bárbara (RR-3) y ampliándose a máximo cinco pisos en Chapinero Alto (RR2). Sin embargo, aún en la vigencia del Acuerdo 7, en 1987, se introdujo el Decreto 1025 que aumentó nuevamente los límites de altura en la ciudad sin mediar un nuevo plan de ciudad. Para las zonas múltiples AMR -Chicó y Sur- la altura máxima se estableció en 19.30 metros, lo que equivale a una altura máxima de seis a siete pisos. Para las zonas residenciales, en Chapinero Alto (RR-2), se establecieron los mismos límites que en AMR, pero en Santa Bárbara (RR-3) se limitó la altura máxima sólo a 13.30 metros, entre cuatro o cinco pisos.

Hasta este punto, los sectores de Chicó y Sur tenían una normativa similar en función de que ambas áreas se consideraban parte del centro expandido de la ciudad. A partir del Acuerdo 6 de 1990, Chicó se consideró nuevamente como residencial mientras que el sector Sur siguió siendo un área de uso mixto. A pesar de esto, se aumentaron los límites de altura en Chicó y se disminuyeron en Sur. Tanto Chicó como 
Santa Bárbara y Chapinero Alto pasaron a tener una categoría de uso de Área Residencial Especializada (código ARE) para proteger a los residentes del cambio de usos. sin embargo, su normativa volumétrica igualmente variaba. Para Chicó se estableció una volumetría 6/8, es decir con un máximo de altura de seis pisos, que podía extenderse a ocho pisos si el predio tenía un frente mayor a 30 metros y un área mayor a $1000 \mathrm{~m}^{2}$. Chapinero Alto fue designado con volumetría 6 , altura máxima seis pisos, y Santa Bárbara tuvo volumetría 4 (es decir, una altura máxima de cuatro pisos) lo que en 1993 disminuía efectivamente los límites de altura para el sector. El sector Sur que mantuvo su zonificación de área de uso mixto, o "Actividad Múltiple" AM, también vio disminuido su límite de altura ya que con volumetría 4 pasó también de una altura máxima de cinco pisos a un máximo cuatro pisos.

El Decreto 190 de 2004 dividió la ciudad en 117 UPZ como procesos de planeación diferenciados que seguirían lo dispuesto en el POT y responderían a los procesos de participación llevando a decretos diferenciados para cada sector de ciudad. Específicamente, la norma de Chicó fue establecida a través de la UPZ 97 Chicó-Lago, y dictaminó para el sector un tratamiento de Consolidación Con Cambio de Patrón. Este cambio aumentó nuevamente los límites de altura generalizado a un máximo ocho pisos, y aumentando a 10 en el caso que los predios tuvieran un frente mayor a 25 metros y un área mínima de $1200 \mathrm{~m}^{2}$. Chapinero Alto fue reglamentado a través de la UPZ 90 Pardo Rubio y fue designado también con tratamiento de Consolidación Con Cambio de Patrón, sin embargo, aquí la norma específica sólo permitió una altura máxima de cinco pisos, reduciendo en un piso el límite establecido en el Acuerdo 6. El sector de Santa Bárbara fue reglamentado a través de la UPZ 16 Santa Bárbara que designó en el barrio un tratamiento de Consolidación Con Densificación Moderada, con una altura máxima de cinco pisos, en este caso aumentando un piso el límite establecido en el Acuerdo 6.

El sector Sur comprendió cuatro UPZ, 37 Santa Isabel, 38 Restrepo, 35 Ciudad Jardín, y 33 Sosiego, predominando también el tratamiento de Consolidación con Densificación Moderada. En este caso, sin embargo, la norma específica en realidad no permitió la densificación, ya que el límite de altura se estableció en tres pisos. Este límite en efecto redujo en un piso las alturas que se permitían anteriormente en el Acuerdo 6. Por tanto, la formulación de la norma a través de las UPZ en los casos de Chapinero Alto y Sur no siguió las normas de mayor jerarquía establecidas en el Decreto 190 y pudo haber restringido su desarrollo.

La Figura 6 compara los límites de altura de los casos de estudio en los planes de zonificación. Como lo indica la tabla, los cambios de altura han sido diferenciados para cada una de las zonas. El aumento de límites de altura ha 
FIGURA 6. RESUMEN DE LÍMITES DE MÁXIMOS DE ALTURA EN PISOS PREDOMINANTES EN LOS SECTORES CASO DE ESTUDIO.

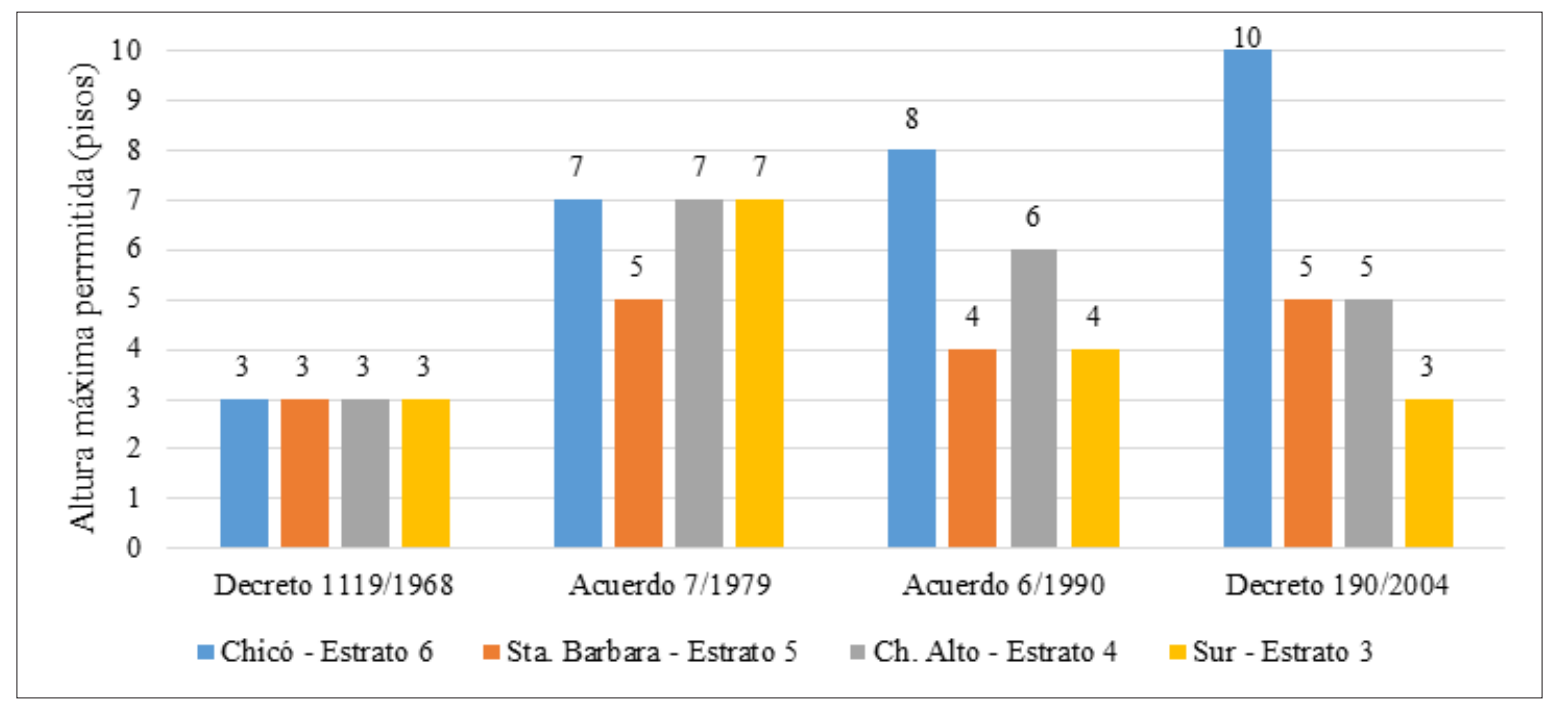

Fuente: Elaboración propia.

sido mucho mayor en Chicó, el segmento con mayor precio de vivienda. Los límites de altura han sido estables en Santa Bárbara-estrato $5-\mathrm{y}$ han disminuido en los segmentos de menores precios Chapinero Alto-estrato 4-y Sur-estrato 3. Esto demuestra que hubo una aplicación diferenciada de las estrategias de densificación que respondieron al PCU en los últimos 30 años, privilegiando al segmento más alto de precio de la vivienda.

La Tabla 1 muestra cómo los cambios de densidad en estas zonas entre 1972 y 2010 no fueron homogéneos. Paradójicamente, pese a que Chicó recibió grandes beneficios -aumentando sucesivamente los límites de altura- la densidad poblacional descendió considerablemente en el período (-39\%), mostrando que la estrategia de densificación no necesariamente aumentó el número de habitantes, sino que, más bien, generó un cambio de uso a comercial y de servicios. Las densidades sí aumentaron de manera considerable en Santa Bárbara (56\%) y marginalmente en Chapinero Alto (5\%), 
mientras descendieron moderadamente en Sur (-11\%) - un hecho consistente con las restricciones en altura que se le han impuesto.

TABLA 1: CAMBIO DE DENSIDADES (HAB./HA) DE LOS SECTORES CASO DE ESTUDIO, 1973 2010.

\begin{tabular}{lllll}
\hline Sector de Estudio & Estrato & 1972 & $2010^{*}$ & Cambio \\
\hline TOTAL BOGOTÁ & - & $214 \mathrm{Hab} . / \mathrm{Ha}$. & $205 \mathrm{Hab} . / \mathrm{Ha}$. & $-4 \%$ \\
\hline Chicó & 6 & $102 \mathrm{Hab} . / \mathrm{Ha}$ & $62 \mathrm{Hab} . / \mathrm{Ha}$ & $-39 \%$ \\
Santa Bárbara & 5 & $73 \mathrm{Hab} . / \mathrm{Ha}$ & $113 \mathrm{Hab} . / \mathrm{Ha}$ & $56 \%$ \\
Chapinero Alto & 4 & $151 \mathrm{Hab} . / \mathrm{Ha}$ & $159 \mathrm{Hab} . / \mathrm{Ha}$ & $5 \%$ \\
Sur & 3 & $253 \mathrm{Hab} . / \mathrm{Ha}$ & $226 \mathrm{Hab} . / \mathrm{Ha}^{*}$ & $-11 \%$
\end{tabular}

Fuente: Documento Técnico de Soporte POT 2000 (DAPD, 2000, p. 89) Programa Integrado de Desarrollo Urbano de la Zona Oriental de Bogotá (DAPD, 1973)* y Densidad población Localidad UPZ 2010 (SDP, 2010).**

* Para Chicó es el promedio de ocho barrios; Santa Bárbara el promedio de seis barrios, Chapinero Alto el promedio de ocho barrios, y Sur el promedio de seis barrios.

**Para el caso Sur la densidad es el promedio de cuatro UPZ. La Figura 7 muestra la evolución de la altura del área construida según su fecha de construcción. El análisis comparativo con el potencial normativo muestra que solo en Chico la construcción en altura y la ampliación del límite normativo evolucionan en el mismo sentido, o sea, usando el potencial normativo cuando está disponible, mientras que los otros sectores muestran una evolución dispar del potencial y la altura de las edificaciones. En Santa Bárbara la construcción en altura aumenta de manera continua en el tiempo aun cuando no existe una ampliación de los límites de altura. Chapinero Alto parece responder a la ampliación de la altura incluida en el Acuerdo 7 en dos momentos diferentes, entre 196878 y luego hasta después de 2004. El sector Sur muestra el porcentaje más bajo de área construida en altura, aun para el período 19681978, cuando la altura permitida en este sector era mayor a la permitida en Chapinero Alto y Santa Bárbara. La altura de las edificaciones en este sector aumenta desde 2004, año en que la norma fue menos favorable en el sector. Este período coincide con un auge de la construcción en la ciudad, lo que corrobora la intuición de la necesidad de una coyuntura 
FIGURA 7. PROPORCIÓN DE ÁREA EN 4 PISOS O MÁS SEGÚN SECTOR DE ESTUDIO Y PERIODO NORMATIVO.

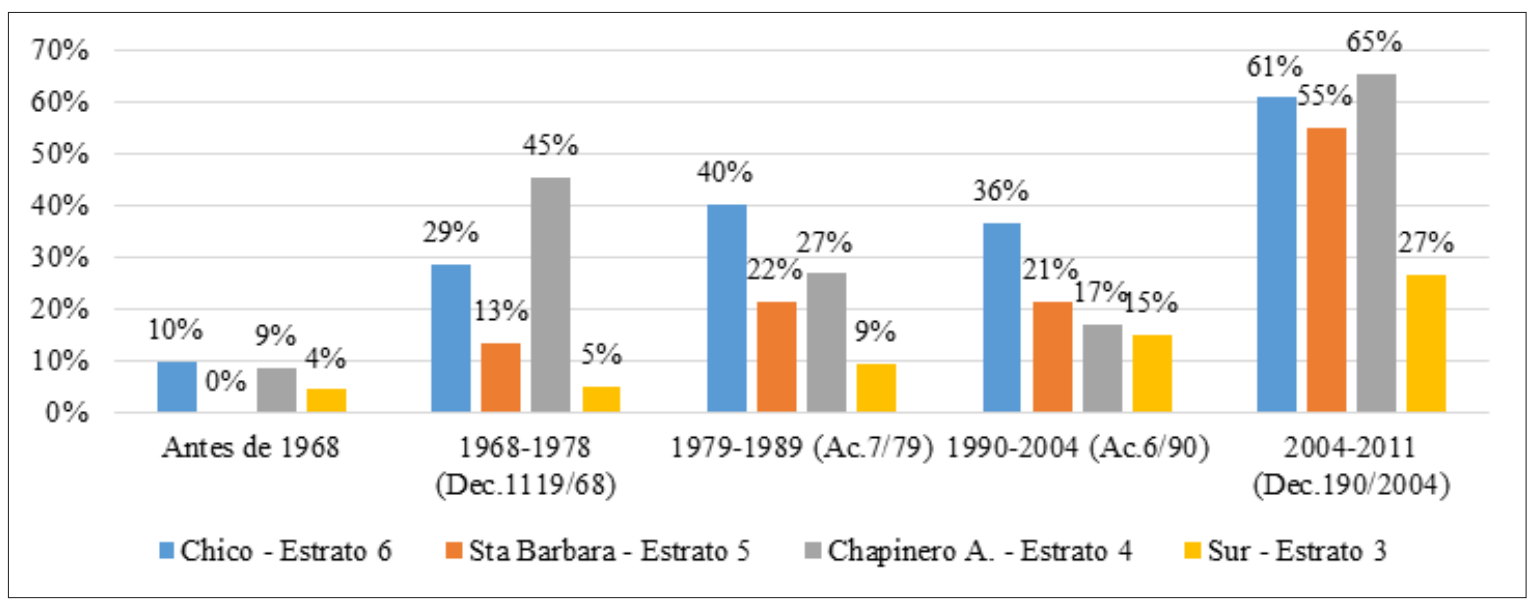

Fuente: Elaboración propia a partir de Catastro Bogotá 2012.

favorable para el aprovechamiento efectivo del potencial normativo. El sector Sur tendría así, antes de 2004, un nivel de precios de la vivienda insuficiente para hacer rentables proyectos en mayores alturas. El sub-aprovechamiento, antes de 2004, del potencial normativo en los sectores diferentes a Chicó parece ser la tendencia general. No obstante, después de 2004 los sectores como Santa Bárbara y Chapinero Alto parecen tener mayor aprovechamiento, pero no es el caso de Sur.

La Figura 8 permite emitir la hipótesis de que un factor explicativo del aumento de la altura de las construcciones es el aumento de los precios de la vivienda observado desde inicios de la década de 2000. Los mayores precios de venta permitirían así, en mayor medida, la rentabilidad de proyectos en altura (incluso para aquellos proyectos que requieren la demolición de viviendas antiguas) llevando también a la densificación de Santa Bárbara y Chapinero Alto. La zona Sur muestra menores alturas, reflejando la menor valorización del precio del suelo y la vivienda en este sector.

Las variaciones de los precios del suelo y de la vivienda merecen un comentario adicional pues, aunque ambos comparten movimientos cíclicos, a largo plazo muestran tendencias 
FIGURA 8. PRECIO DEL SUELO Y DE LA VIVIENDA SEGÚN SECTOR DE OBSERVACIÓN, 19702011.

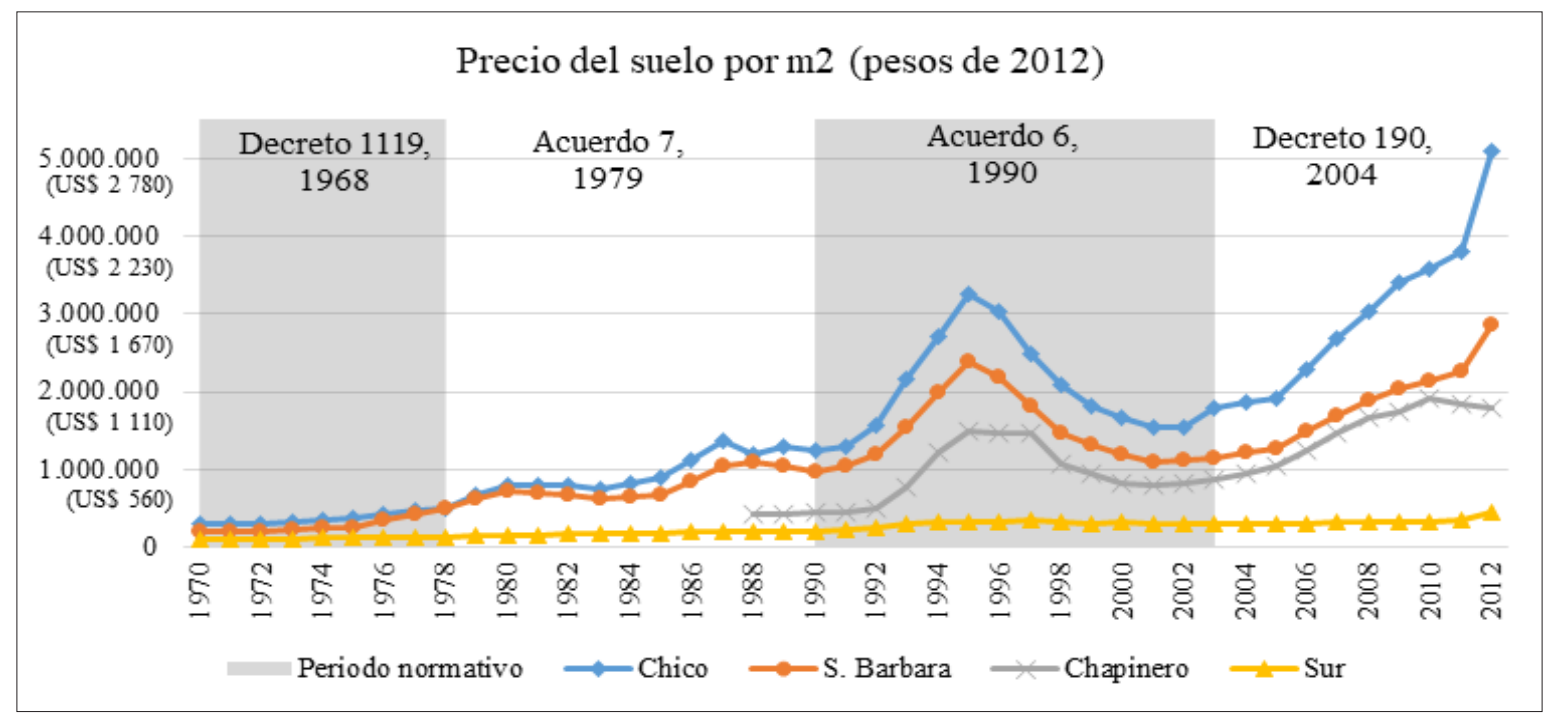

Fuente: Elaboración propia a partir de Lonja de Propiedad Raíz de Bogotá y Observatorio CEDE.

dispares: mientras los precios del suelo aumentan, los precios de la vivienda, aunque diferenciados entre estratos, parecen fluctuar alrededor de un valor estable en el largo plazo. La Tabla 2 ilustra este punto, comparando el valor inicial de cada variable por sector al inicio y al final del período de observación. En Chicó un metro cuadrado de suelo costaba, en precios reales, 17,26 veces más en 2012 respecto a 1970 , mientras que una vivienda cuesta 1,08 veces más en el mismo período. De esta manera, la valorización del suelo es mayor para todos los sectores de estudio, pero mucho mayor en los sectores de estratos 4, 5 y 6. Esta evolución dispar muestra los límites de las intenciones de zonificación de la ciudad resultantes de la interacción entre la norma y el mercado inmobiliario. Los terrenos ubicados en sectores de mayores precios de la vivienda tienen una valorización considerablemente mayor a aquellos situados en sectores de menores precios; en este sentido la zonificación de densificación no contribuye a la reducción de las diferencias socio-espaciales de Bogotá, 
sino que se suma a los otros factores de diferenciación, como las diferencias espaciales de precios de la vivienda.

TABLA 2: VARIACIÓN ACUMULADA REAL DE PRECIOS SEGÚN SECTOR, 1970-2012.

\begin{tabular}{llll} 
Sector de Estudio & Estrato & Variación Precio del Suelo & Variación Precio Vivienda \\
\hline Chicó & 6 & 17,26 & 1,08 \\
\hline Santa Bárbara & 5 & 14,52 & 1,08 \\
Chapinero Alto & 4 & 4,23 & 1,24
\end{tabular}

Sur 3 3,98 llevó a su homdgę̉eización en la zona, sino, Fuente: Elaboración propia a partir de Lonja de Propiedad Raíz más bien, a que la inversión del sector privado de Bogotá y Observatorio CEDE.

\section{Conclusiones}

El análisis general y particular, por sectores, de la política de PCU y la densificación nos lleva a plantear una conclusión general para un debate teórico alrededor de la valorización del suelo y la vivienda en relación a los PCU y los factores de jerarquización social. En general, la política del PCU fue exitosa, pues mientras la mayoría de las ciudades del mundo perdieron densidad a lo largo de la segunda mitad del siglo XX, Bogotá logro mantener una densidad alta. En su objetivo de densificación de la zona central, sin embargo, la política tuvo problemas ya que el aumento en los límites de altura no y los cambios efectivos de densidad hubieran de ser diferenciados, privilegiando las zonas con los estratos más altos -la 4, 5 y 6- que apenas constituyen cerca de un 25\% de la ciudad.

Esto ha dado beneficios a las familias de ingresos medios o altos que viven, o buscan vivir, en estos sectores pues los grandes aumentos en el precio del suelo no se han transferido a aumentos en el precio de la vivienda. Como lo muestra el estudio, este beneficio se ha dado, en gran medida, por el alto aprovechamiento por parte de los promotores de la normativa en estas áreas. Los estratos medios, ejemplificados en el caso de Santa Bárbara y Chapinero Alto, no fueron afectados de manera importante en las primeras décadas de la política del PCU, pero experimentaron una densificación importante desde 2004. Llama la atención "Sur", la zona de estrato más bajo, donde el 
suelo no se valorizó como en los otros sectores -habiendo un bajo aprovechamiento por parte de los promotores- y la norma de alturas, paradójicamente, se revirtió hacia abajo. Esto pudo haber contribuido a que los precios de la vivienda hayan aumentado en la zona Sur, desde la implementación del PCU, a un ritmo mayor que en otros sectores, afectando a las familias de ingresos menores. Estas diferencias, tanto en la aplicación de la norma como en su aprovechamiento por parte de los promotores, pueden haber impedido la integración urbana de la ciudad en los últimos cincuenta años, perpetuando un patrón segregado.

\section{Agradecimientos}

Este trabajo fue financiado por la Pontificia Universidad Javeriana y la Universidad Sergio Arboleda de Bogotá

\section{Referencias bibliográficas}

Addison, C., Zhang, S., y Coomes, B. (2013). Smart growth and housing affordability: A review of regulatory mechanisms and planning practices. Journal of Planning Literature, 28(3), 215-257. https://doi.org/10.1177/0885412212471563

Aguilar, A. y Olvera, G. (1991). El control de la expansión urbana en la ciudad de México: Conjeturas de un falso planteamiento. Estudios Demográficos y Urbanos, 6(1), 89-115. https://doi.org/10.24201/edu.v6il.804

Aurand, A. (2010). Density, housing types and mixed land use: Smart tools for affordable housing? Urban Studies, 47(5), 1015-1036.

https://doi.org/10.1177/0042098009353076

Borrero Ochoa, 0. (2010). Avalúo de inmuebles y gestión del suelo. Métodos de valorización. Medellín: Universidad Nacional de Colombia.

Brites, W. F. (2017). La ciudad en la encrucijada neoliberal. Urbanismo mercado-céntrico y desigualdad socio-espacial en América Latina. urbe. Revista Brasileira de Gestão Urbana, 9(3), 573-586.

https://doi.org/10.1590/2175-3369.009.003.aol4

Cortés Solano, R. (2007). Del urbanismo a la planeación en Bogotá (1900-1990) esquema inicial y materiales para pensar la trama de un relato. Bitácora Urbano Territorial, 1(11), 160-213.

Departamento Administrativo de Planificación Distrital. (1964). La planificación en Bogotá. Bogotá: Autor.

Departamento Administrativo de Planificación Distrital. (1973). Programa integrado de desarrollo urbano de la zona oriental de Bogotá. Bogotá: Autor.

Departamento Administrativo de Planificación Distrital. (2000). Plan de Ordenamiento Territorial de Bogotá POT. Bogotá: Autor.

Departamento Administrativo de Planificación Distrital. (2004). La estratificación en Bogotá, D.C. y estudios relacionados 1983-2004. Bogotá: Autor. 
Dawkins, C. J. y Nelson, A. C. (2002). Urban containment policies and housing prices: An international comparison with implications for future research. Land Use Policy, 19(1), 1-12. https://doi.org/10.1016/S0264-8377(01)00038-2

Dillon, B. y Cossio, B. (2011). La mercantilización de lo intangible: la asignación de valor hedónico al suelo urbano en ciudades intermedias en expansión. Revista Geográfica de América Central, 2(47E), 1-17.

Downs, A. (2002). Have housing prices risen faster in Portland than elsewhere? Housing Policy Debate, 13(1), 7-31.

https://doi.org/10.1080/10511482.2002.9521432

Encinas, F., Marmolejo, C., y Aguirre, C. (2016). El impacto de los proyectos inmobiliarios y sus atributos de sustentabilidad sobre el valor del suelo: icausa o consecuencia? dos estudios de casos para Santiago de Chile. Hábitat Sustentable, 6(2), 70-79.

Estupiñan, N. (2011). Impactos en el uso del suelo por inversiones de transporte público masivo. Revista de Ingeniería, (33), 34-43-43.

Griffin, E. y Ford, L. (1980). A model of Latin American city structure. Geographical Review, 70(4), 397-422.

https://doi.org/10.2307/214076

Islam, K. S. y Asami, Y. (2009). Housing market segmentation: A review. Review of Urban $E$ Regional Development Studies, 21(2-3), 93-109. https://doi.org/10.1111/j.1467-940X.2009.00161.x
Jaramillo, S. (2009). Hacia una teoría de la renta del suelo urbano. Bogotá: Universidad de los Andes.

Jaramillo, S. \& Cuervo, N. (2014). Precios inmobiliarios de vivienda en Bogotá 1970-2013. Bogotá: Universidad de los Andes.

Jaramillo, S., Parias, A., y Llano, M. C. (1993). La estructura de la edificación y de la producción de vivienda en Bogotá, Medellín y Cali. Bogotá: CEDE, Uniandes.

Jun, M.-J. (2006). The effects of Portland's urban growth boundary on housing prices. Journal of the American Planning Association, 72(2), 239-243. https://doi.org/10.1080/01944360608976742

Mathur, S. (2014). Impact of urban growth boundary on housing and land prices: Evidence from King County, Washington. Housing Studies, 29(1), 128-148.

https://doi.org/10.1080/02673037.2013.825695

Mathur, S. (2019). Impact of an urban growth boundary across the entire house price spectrum: The two-stage quantile spatial regression approach. Land Use Policy, 80, 88-94. https://doi.org/10.1016/j.landusepol.2018.09.011

Meen, G. y Andrew, M. (2004). On the use of policy to reduce housing market segmentation. Regional Science and Urban Economics, 34(6), 727-751. https://doi.org/10.1016/j.regsciurbeco.2003.11.003

Omer, I. y Goldblatt, R. (2012). Urban spatial configuration and socio-economic residential differentiation: The case of Tel Aviv. 
Computers, Environment and Urban Systems, 36(2), 177-185.

https://doi.org/10.1016/j.compenvurbsys.2011.09.003

Phillips, J. y Goodstein, E. (2000). Growth management and housing prices: The case of Portland, Oregon. Contemporary Economic Policy, 18(3), 334-344.

https://doi.org/10.1111/i.1465-7287.2000.tb00030.x

Quintana, J., Ojeda, A., y García, J. F. (2018). Factores que explican el valor del suelo. Caso Hermosillo, Sonora, México. Contexto, 12(16).

Roca Cladera, J. (1983). Teorías alternativas para la formación espacial del valor del suelo. El caso de Barcelona. Annals d'arquitectura, (2), 36-49.

Rodríguez, D. A. y Targa, F. (2004). Value of accessibility to Bogotá's bus rapid transit system. Transport Reviews, 24(5), 587-610. https://doi.org/10.1080/0144164042000195081

Rodríguez, D. A., Vergel-Tovar, E., y Camargo, W. F. (2016). Land development impacts of BRT in a sample of stops in Quito and Bogotá. Transport Policy, 51, 4-14.

https://doi.org/10.1016/j.tranpol.2015.10.002
Salazar-Ferro, J. (2017). Construir la ciudad moderna: Superar el subdesarrollo. Enfoques de la planeación urbana en Bogotá (1950-2010). Bogotá: Universidad Nacional de Colombia.

Saldarriaga-Roa, A. (2000). Bogotá siglo XX: urbanismo, arquitectura y vida urbana. Bogotá: Alcaldía Mayor de Bogotá D.C.

Schnare, A. B. y Struyk, R. J. (1976). Segmentation in urban housing markets. Journal of Urban Economics, 3(2), 146-166. https://doi.org/10.1016/0094-1190(76)90050-4

Secretaría Distrital de Planeación. (2010). Densidad población Localidad UPZ 2010. Bogotá: Autor.

Secretaría Distrital de Planeación. (2016). Proyecciones de población 2016-2020. Estadísticas. Bogotá: Autor.

Uribe-Mallarino, C. (2008). Estratificación social en Bogotá: De la política pública a la dinámica de la segregación social. Universitas humanistica, 65(65), 139-171.

Yunda, J. G. (2019). Densificación y estratificación social en Bogotá: Distribución sesgada de la inversión privada. EURE, 45(134).

https://doi.org/10.4067/S0250-71612019000100237 


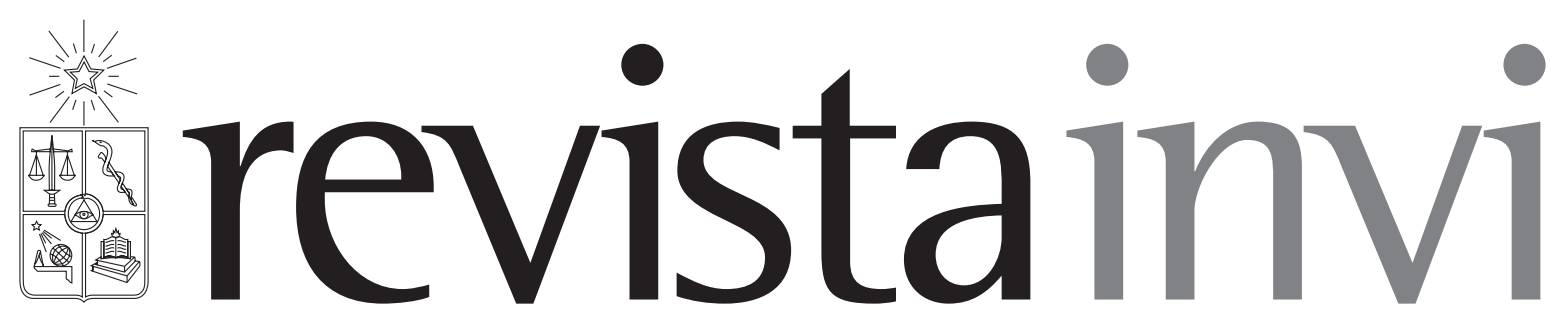

Revista INVI es una publicación periódica, editada por el Instituto de la Vivienda de la Facultad de Arquitectura y Urbanismo de la Universidad de Chile, creada en 1986 con el nombre de Boletín INVI. Es una revista académica con cobertura internacional que difunde los avances en el conocimiento sobre la vivienda, el hábitat residencial, los modos de vida y los estudios territoriales. Revista INVI publica contribuciones originales en español, inglés y portugués, privilegiando aquellas que proponen enfoques inter y multidisciplinares y que son resultado de investigaciones con financiamiento y patrocinio institucional. Se busca, con ello, contribuir al desarrollo del conocimiento científico sobre la vivienda, el hábitat y el territorio y aportar al debate público con publicaciones del más alto nivel académico.

Director: Dr. Ricardo Tapia Zarricueta, Universidad de Chile, Chile.

Editor: Dr. Luis Campos Medina, Universidad de Chile, Chile.

Editor asistente: Dr. Walter Imilan, Universidad de Chile, Chile.

Coeditora: Srta. Sandra Rivera, Universidad de Chile, Chile.

\section{COMITÉ EDITORIAL:}

Dr. Victor Delgadillo, Universidad Autónoma de la Ciudad de México, México.

Dra. María Mercedes Di Virgilio, CONICET/ IIGG, Universidad de Buenos Aires, Argentina.

Dra. Irene Molina, Uppsala Universitet, Suecia.

Dr. Gonzalo Lautaro Ojeda Ledesma, Universidad de Valparaíso, Chile.

Dra. Suzana Pasternak, Universidade de São Paulo, Brasil.

Dr. Javier Ruiz Sánchez, Universidad Politécnica de Madrid, España.

Dra. Elke Schlack Fuhrmann, Pontificia Universidad Católica de Chile, Chile.

Dr. Carlos Alberto Torres Tovar, Universidad Nacional de Colombia, Colombia.

Sitio web: http://www.revistainvi.uchile.cl/

Correo electrónico: revistainvi@uchilefau.cl

Licencia de este artículo: Creative Commons Atribución-Compartirlgual 4.0 Internacional (CC BY-SA 4.0) 